\title{
Schizophrenia, Culture, and Culture-Bound Syndromes
}

\author{
Kevin Volkan ${ }^{1,2}$ \\ ${ }^{1}$ Department of Psychology, California State University Channel Islands, Camarillo, CA, United States \\ ${ }^{2}$ Graduate Medical Education Program, Community Memorial Health System, Ventura, CA, United States \\ Email: kevin.volkan@csuci.edu
}

\begin{abstract}
Schizophrenia is a severe mental illness that affects people all around the world. It presents in many different contexts, across geographic boundaries, and in different ways. Rates of schizophrenia seem generally to be the same regardless of geographical location, though there is some evidence that those in developed nations have a higher incidence of the disorder. Also, immigrants who relocate to areas where their culture has little, or no representation are at more risk for schizophrenia. While the prevalence of schizophrenia is similar around the world, the presentation of the disorder can vary widely, depending on the cultural, religious, and supernatural beliefs native to specific areas. Examples of varying types of presentation of schizophrenia, including culture-bound disorder variants, can give insight into the ways in which people from across the world make sense of this devastating disease, and ways in which they attempt to treat it.
\end{abstract}

Keywords: schizophrenia, culture-bound syndromes, Windigo psychosis, Qi Gong psychosis, Amafufunyana, Saora disorder

\section{$1 \quad$ Introduction}

Schizophrenia represents a wide variety of mental disorders that present with various psychotic symptoms. These symptoms include disordered thoughts, cognitive impairments, and perceptual impairments which, culminate in a loss of connection to reality. Delusional beliefs are common and, in many cases are associated with both auditory and/or visual hallucinations. These symptoms cause a number of non-normative behavioral and personality changes that impact interpersonal functioning, health, and the ability for the sufferer to take care of him or herself.

Psychotic illnesses are now seen as variations of schizophrenia (American Psychiatric Association, 2013). In the past each disorder such as schizophrenia, schizophreniform disorder, schizoaffective disorder, delusional disorder, brief psychotic disorder, substance/medication induced psychotic disorder, psychotic disorder due to another medical condition, unspecified schizophrenia and other psychotic disorder had its own separate diagnostic category. However, schizophrenia and other psychotic disorders have many commonalities. They seem to differ from schizophrenia in only a few key characteristics, manifesting along a spectrum. Schizophrenia and other related disorders seem to mainly vary by duration, symptomatic presentation, and symptomatic content. Schizophrenia and its variants present with positive, negative, or mixed symptoms. Overt delusions, auditory, visual, and tactile hallucinations are examples of positive symptoms while flat affect, alogia, avolition, anhedonia, and impairment of attention are examples of negative symptoms. People suffering from schizophrenia often have both positive and negative symptoms. It is important to realize that for schizophrenia to be diagnosed the symptomology must be considered bizarre compared to normal behavior found in the sufferer's culture. Impairment in cognition often accompanies schizophrenia which makes social interaction difficult (Dion \& Dellario, 1988; Rossello et al., 2013). Schizophrenia is fairly common with prevalence rates ranging from $.2 \%$ to $1.5 \%$ of the world population. For a review of the current state of knowledge about schizophrenia see Volkan (2020).

\section{$2 \quad$ Schizophrenia and Culture}

It is known that the presentation and interpretation of schizophrenia, including its associated behavior and symptoms, can differ across cultures. For instance, people who have origins in the Indian 
subcontinent tend to present with excessive worry and irritability, while Afro-Caribbean people present with delusions and paranoid ideation (Saravanan et al., 2007b). Turkish patients suffering from schizophrenia were found to be more ambivalent, exhibiting more inappropriate and inane behavior than American patients suffering from the disease. The Turkish schizophrenia sufferers also displayed more euphoric behavior, while being more depersonalized, disorganized and dissociated when compared to patients suffering from schizophrenia in America (Çetingök et al., 1990).

In his study of Irish and Italian schizophrenic patients, Opler (1959) found that the Italians were more likely to exhibit overtly homosexual behaviors, have other behavioral disorders (which we might interpret as positive symptoms), be more rejecting of authority, have less fixed delusions, have more somatic complaints, and less chronic alcoholism than their Irish counterparts. The Irish group of people suffering from schizophrenia was found to be more pre-occupied with sin and guilt, less likely to have behavioral disorders, more likely to be compliant towards authorities, have more fixed delusions, have less somatic complaints, and have higher levels of chronic alcoholism than the Italian patients. Opler concluded that it was possible to distinguish different groups among his schizophrenic patients by their distinct cultural backgrounds and the patterns which each cultural group expressed through the stress of family conflicts. Irish families were characterized by having the mother as the central authority figure while fathers were seen as shadowy ineffectual figures in the home. The Irish male patients had been infantilized to some degree and not allowed to individuate. This resulted in anxiety and hostility being related to their mothers in most of the Irish patients. The Italians demonstrated a pattern opposite of the Irish patients, with father figures (fathers and older male siblings) being dominant in the home. This brought out expressions of hostility when there were poorly repressed conflicts with a father figure in the home. The father figures showed marked rejection of the patients, with mothers also subtly rejecting the patients and favoring the elder sons. The mothers were also neglected by the fathers and they encouraged impulsiveness and hostile acting out on the part of the patients with their father figures. This resulted in the Italian patients showing emotional overflow in the form of talking too much, curious mannerisms, overexpressed grinning and laughing, and assaultiveness. They were also more likely to attempt suicide. This resulted in the Italian patients not being as paranoid as the Irish.

The Irish patients suffering from schizophrenia demonstrated more constriction of emotion, as well as a tendency to replace action with fantasy. This resulted in more delusions and paranoia. Some of the delusions took the form of persecutory thoughts related to guilt and sin as well as distortion of body image in some cases. Several of the Irish cases expressed these types of delusions by referring to a vagina dentata - a toothed, castrating vagina.

Another study found that individuals suffering from schizophrenia who live in developing nations are three times more likely to exhibit violent behavior than schizophrenia sufferers from developed nations. Assaultive behavior was found to be associated with positive symptoms as well as problems with alcohol abuse (Volavka et al., 1997).

\section{$3 \quad$ Causes and Beliefs about Schizophrenia}

Even though presenting symptoms may be different across cultures, the underlying schizophrenia processes can be seen as the same (Saravanan et al., 2007b). However, the attributed causes of schizophrenia can vary according to culture and exposure to Western biomedical conceptions of the disease. In one study Africa-Americans with schizophrenic family members reported biological causes as the most common explanation of the disease. Personality esoteric, and societal explanations were also important to family members of schizophrenic individuals (Mulder, 2009).

Another study compared British and Chinese beliefs about the origins, behavioral manifestations, and treatment of schizophrenia. Chinese people were found to have more religious and superstitious beliefs about the cause of schizophrenia and were more likely to frame treatment for the disease around nonscientific beliefs and traditional Chinese medicine. British people explain the causes of schizophrenia as biological, psychological, and sociological terms and framed treatment of the disease according to this view. The Chinese had more negative attitudes and beliefs about schizophrenic behavior than the British (Furnham \& Wong, 2007).

In a study in Bali, close relatives were more likely to believe in supernatural explanations as the cause of schizophrenia than natural causes. Compared with relatives who listed a natural cause as most 
important (14 relatives, or 36 percent), relatives who believed in supernatural causes of schizophrenia were generally older, had less education, and had a family member suffering from schizophrenia who had not received psychiatric treatment (Kurihara et al., 2006).

In South India $70 \%$ schizophrenic patients in one study attributed their disease to spiritual and mystic elements, while $22 \%$ believed in a biomedical model of their illness. Schizophrenic patients who believed in a biomedical model of the disease had higher levels of insight. Being female, having a low level of education, and use of traditional healers was associated with spiritual/mystical beliefs about schizophrenia, while having a high level of insight was associated with biomedical beliefs about the illness (White et al., 2008). While some insight was inversely related to symptom severity, there was a stronger association of insight with anxiety, wanting to seek help, perception of change. The ability to understand schizophrenic symptoms as part of a disease in self and others, as opposed to supernatural forces, was strongly associated with insight. However, this view of insight may fail to account for culturally valid explanatory frameworks for schizophrenia (Ptak \& Lachmann, 2003). In a study examining attribution of emotional reactions to schizophrenia, Mexican individuals perceived negative schizophrenic symptoms as less controllable when compared to the perceptions of Anglo-American individuals (Weisman \& López, 1997).

\section{$4 \quad$ Religious Beliefs and Schizophrenia}

There may be a relationship between harmful religious/supernatural beliefs and schizophrenia. Bhavsar and Bhugra (2008) suggest that delusions can be generated and maintained through family expectations and religious rituals. Delusions supported by religion may also lead to harm to self or others. Certainly, religious delusions may have neurobiological origins. Studies have found that patients with post-epileptic seizure psychosis may experience hyper-religiosity. Although there are surely psychological and cultural factors at play, there is a strong likelihood of a neurological involvement. This involvement may include the limbic system and the neocortex. It may be that the so-called 'ecstatic' religious experience is related to changes in the frontal and temporal regions of the right hemisphere of the brain (Devinsky \& Lai, 2008).

\section{$5 \quad$ Effects of Schizophrenia across Cultures}

In addition to beliefs about the causes and how to treat schizophrenia, rates of marriage and fertility of people suffering from schizophrenia may differ by culture. As might be expected individuals suffering from schizophrenia are less likely to marry and have children than normal people. It is not known, however, whether this is due to the effects of the illness itself or the impaired social cognition or social milieu among people suffering from schizophrenia. One study compared marriage, relationship stability, and fertility rates of White British, Caribbean and Asian subjects suffering from schizophrenia. It was found that British and Caribbean subjects (but not Asians) had decreased rates of stable relationships, marriage, fertility and number of children compared to normal controls. These findings suggest a decrease in marriage and sexual behavior are associated with schizophrenia, but that this is influenced by society and culture (Hutchinson et al., 1999).

\section{$6 \quad$ Immigration and Schizophrenia}

There is an immense body of literature and a long history of research linking schizophrenia to immigration. Ødegård (1932) was one of the first to study mental illness among immigrants. He hypothesized that Norwegian immigrants to the United States immigrate had poor social adaptation before they immigrated and were essentially "weak" and predisposed to mental illness. In other words, there was a selection bias, whereby people predisposed to insanity were more likely to immigrate than the general population.

It is likely that individuals suffering from schizophrenia who are immigrants may have a different cultural background that the professionals who provide their treatment (Fearon et al., 2006; Gibson et al., 2013; Leão et al., 2006; Simpson, 1995). Therefore, it is important to treat schizophrenia among immigrants in ways that mobilize cultural explanations. There are many case studies in the literature 
that provide positive examples of this way of working with patients suffering from schizophrenia (Hwang, 2007; Kastrup et al., 2008; Mausbach et al., 2008; Saravanan et al., 2007a).

Darker skinned individuals who migrate to England and the Netherlands are known to have high rates of schizophrenia. Also, among non-white, non-immigrants, the incidence of schizophrenia goes up as when their ethnic presence is reduced in the place where they live. One explanation put forward to explain this phenomenon is "social defeat". This term is derived from ethological studies where one animal physically defeats another animal. The defeated animal must then constantly display submissive behavior. This type of defeat and submissive behavior has been shown in rats to increase dopaminergic activity in the meso-limbic system which is thought to be associated with schizophrenia. Isolation increases this effect while removal from the physically dominating animal reduces it. The idea that this sort of dynamic could increase schizophrenia rates among non-white people who find themselves living in a white-dominant society is quite plausible (Luhrmann, 2007). Looked at from another view, sociocentric indicators that were related to ethnic culture were found to mediate differences in symptoms in Latin and Black schizophrenia sufferers, compared to white patients suffering from the disease. These sociocentric indicators were found to reduce symptoms for non-white patients suffering from schizophrenia in the study. This may demonstrate that people suffering from schizophrenia who have strong cultural support may have reduced symptoms of the disorder (Brekke \& Barrio, 1997).

\section{$7 \quad$ Culture-Bound Schizophrenia}

There are various syndromes that appear related to schizophrenia and its variants found among the cultures of the world. Opler (1959) says:

...schizophrenias are not a collection of air-tight entities, since different cultural backgrounds defined variations in family and social structure, reflecting into pathology. As such schizophrenias could highlight, rather than obscure, severely emotionalized conflicts rooted in culture. (pps. 430-431).

Some examples of culture related schizophrenic-like syndromes are presented below. This list is by no means exhaustive but should illuminate both some differences and similarities in the presentation of schizophrenic-like illnesses found across cultures worldwide.

In addition to looking at expressions of schizophrenic illness by different cultural groups, it is possible to also look at distinct related syndromes that have arisen in various cultures. Four culture-bound disorders are presented as brief, but specific examples of how culturally related syndromes related to psychosis can be expressed in different cultures. These examples, Wendigo Psychosis, Qi Gong Psychosis, Amafufunyana, and Saora Disorder share many similarities in symptoms, but differ in how they develop, initial present, and resolve.

\section{Wendigo Psychosis}

"What are you doing Bob?" I turned to meet the stolid mahogany visage of Native American wilderness guide Stanley Owl, who was portaging canoes and gear for a group of fishermen.

"We're shooting a movie," I said. "I see that." Stan's dark eyes flickered over the scene. "But what are YOU doing?" "Uh...well...". I realized that Stanley would not approve my venture. "I'm going to take the canoe by myself up around the base of the falls so I'll kind of be silhouetted against the foam...then take the main current and shoot the rapids past the camera."

"Can't do that," Stanley stated evenly.

"What do you mean I can't?"

"There's a wendigo in those rapids," Stanley replied without a flicker of emotion.

"Wendigo? Ah, come on, Stan, that's a lot of old Indian superstition...you don't believe in that stuff, do you?" 
Stan's eyes flickered a trifle. "Five years ago a Forest Service ranger and I tried to run it. The canoe got torn apart and we both got smashed up pretty bad. He was in the hospital for three weeks."

"That wasn't any wendigo, you guys just screwed up."

"No..." Stan said softly. "There's something in there. You can't make it Bob" (Cary, 1996, pps. 111-112)

In the story above Bob indeed tries to run the rapids and has a strange mishap that destroys his boat and threatens his life. He takes the existence of the wendigo more seriously afterwards. What is this supposed wendigo creature?

Wendigo psychosis (sometimes transliterated as Wendego, Weetego, Windego, Widigo, Windigo, etc.) is a culture-bound syndrome found among Algonquin speaking Native Americans which include the Cree, Innu, Naskapi, Ojibwe, and Saulteaux peoples. Wendigo supposedly means "the evil one that devours" in the Cree language. The Wendigo psychosis is the so-called delusional belief that one will turn into an evil cannibalistic monster or evil spirit. This can be accompanied by schizophrenic-like negative or positive symptoms including paranoia. There are also cultural beliefs about the Wendigo that support the syndrome in individuals. The Wendigo is a creature that was once a man. But because he is starving in an isolated winter environment, the man begins to crave human flesh, eventually succumbing to his cannibalistic desires, turning into a monster or an unseen evil spirit. The monster or spirit is malevolent man eater who also acts with hostility towards those it encounters. Later, after the incursion of the white man, the Wendigo is also seen as a nature spirit who keeps nature in balance, taking vengeance against those who disturb this balance. This meaning is clear in this account (Lindberg, 1974):

"But when Pop asked again about the varmints pressing in from the hills the way they did, then John said something about the spirit of the season. What's that? snaps Pop, not believing he heard right. Wendigo. That's our name for him, says John. And who might that be? When the year runs as it always does, then Wendigo stays asleep, because he knows we do not need him. But when the weather turns bad, and the rains dry up, and a hard winter is coming, then Wendigo comes close to us to help us in our need. Is that what you were doing in the woods for three days, praying for help from a heathen woods devil? John looked at Pop in something of the way that he looked at Brady's rifle when Brady threw him off his land. Then he looked far off at the woods and spoke in a flat voice: We do not pray to beg. We make ourselves clean and open to the spirit. We go a long way alone, and we do not eat or drink or sleep. We make a gift of ourselves because Wendigo keeps the good seasons from us only when we have done wrong." (p. 9)

This story ends with the bad guy, Brady, being attacked by the Wendigo and spirited away never to be seen again, and in all likelihood eaten by the monster.

There has been some speculation that the Wendigo (as well as other cryptids, such as the Toonijuks of the Eskimos, the Alaskan Devils of Thomas Bay, and the Sasquatch of British Columbia), may be remnants of sub-hominid populations that lived on the American continent before proto-Native American people migrated across the Bering Strait (Sanderson, 1963).

People supposedly begin to suffer from the delusion that they will become a Wendigo during periods of starvation. One of the theories about the disorder was that it was due to either lack of fat in the diet or a deficiency in some vitamin or enzyme (Rohrl, 1970). This theory has for the most part been debunked since other people living in similar conditions and subject to restricted caloric intake during the winter months do not report turning into cannibalistic monsters. In a much older case history immoderate singing and dancing was thought to protect against becoming a Wendigo (McGee, 1972). It is possible that that some institutionalized cannibalism existed among the Algonquin people and that the Wendigo myth provides some framework for the act of endo-cannibalism when exo-cannibalism is not possible. McGee (1972) offers us this explanation though it concerns Native people somewhat to the East of the Algonquins:

During the period when the windigo is most active people are dispersed in small extended family or nuclear family camps. Who would be eaten if there existed a choice between a kinsmen and non-kinsmen? One harsh winter the Micmac near Miscou consumed a Basque boy left among them to learn their language... Although I have not examined all 
cases of early cannibalism for the sub-arctic it would appear likely that the victim was chosen on the basis of whose relatives offered the least threat and who offered the most meat. (p. 245)

Given that disorders such as Piblokto have been shown to be caused by over consumption of vitamin A among the Inuit, nutritional causes of Wendigo may deserve further study using more modern nutritional assessment methodology (Landy, 1985).

Wendigo psychosis has also been related to severe anxiety neurosis centered around food among the Ojibwa people. This manifests as delusions, paranoia, depression, violent behavior and obsession with cannibalism which are the hallmarks of Wendigo psychosis (Landes, 1938). Some doctors treating Wendigo psychosis make the case for it being a conversion syndrome (Hagen \& Schokking, 1990).

One startling case of Wendigo psychosis gives some psychological insight into the psychodynamics of the disorder (Hallowell, 1936):

\begin{abstract}
"One morning a young man of about 20 years of age on getting up, said he felt a strong inclination to eat his sister; as he was a steady young man, and a promising hunter, no notice was taken of this expression; the next morning he said the same and repeated the same several times in the day for a few days. His parents attempted to reason him out of this horrid inclination; he was silent and gave them no answer; his sister and her husband became alarmed, left the place and went to another camp. He became aware of it and then said he must have human flesh to eat, and would have it; in other respects, his behavior was cool, calm and quiet. His father and relations were much grieved; argument had no effect on him, and he made them no answer to their questions. The camp became alarmed, for it was doubtful who would be his victim. His father called the men to a council, where the state of the young man was discussed, and their decision was, that an evil spirit had entered into him, and was in full possession of him to make him become a Man Eater (a Weetego). The father was found fault with for not having called to his assistance a Medicine Man, who by sweating and his songs to the tambour and rattle might have driven away the evil spirit, before it was too late. Sentence of death was passed on him, which was to be done by his father. The young man was called ... [and] ... informed of the resolution taken, to which he said, "I am willing to die"; the unhappy father arose, and placing a cord about his neck strangled him, to which he was quite passive; after about two hours, the body was carried to a large fire, and burned to ashes, not the least bit of bone remaining. This was carefully done to prevent his soul and evil spirit which possessed him from returning to this world and appearing at his grave; as they believe the souls of those who are buried can, and may do, as having a claim to the bones of their bodies. It may be thought that the council acted a cruel part in ordering the father to put his son to death, when they could have ordered it by the hands of another person. This was done, to prevent the law of retaliation; which had it been done by the hands of another person, might have been made a pretext of revenge by those who were not the friends of the person who put him to death. Such is the state of society where there are no positive laws to direct mankind." (p. 38).
\end{abstract}

This remarkable case of Wendigo psychosis presents a number of psychological mechanisms at work. The young man at the center of the story shows evidence of negative symptoms of schizophrenia as well as a persistent delusion. Surprisingly, within his delusion is an obvious oedipal conflict. The young man wants to eat his sister. It is fairly easy to read a sexual intent and, indeed inuendo, into this desire. The sister is already married and presumably older and a mother-figure to the young man. The father has to step in to prevent the eating of the sister and is obliged to strangle the young man - an act of killing reminiscent of castration.

\title{
$9 \quad$ Qi Gong Psychosis
}

While the DSM V (American Psychiatric Association, 2013) does not mention Qi gong psychosis, the previous version (DSM-IV) did, though not in conjunction with schizophrenic illness (American Psychiatric Association, 2000). Qi gong psychosis can be used to identify psychoses related to the 
traditional Chinese practice of Qi Gong exercises or to other meditation practices found mostly in the far East (Hwang, 2007).

Qi Gong is generally a type of exercise where body movements are coordinated with specific breathing patterns, visualization or imagined feelings inside the body. There are many hundreds of different Qi Gong exercises that make it hard to generalize about this practice. For the most part, Qi Gong practice is done to prevent illness, to treat illness, and as a spiritual practice. Each of these different kinds of Qi Gong has separate kinds of practices, though some do overlap. Qi Gong works by balancing, promoting and maintaining the flow of Qi in the body. Qi, which is key to understanding the traditional conception of the body in China, is a type of universal energy that flows not only through the body but also throughout the world. The body is seen as a microcosm of the macrocosmic universe. The body becomes diseased when the Qi in the body becomes unbalanced, (deficient or excess), or flows improperly, (stagnant or out of control). Qi Gong practice aims to correct these types of imbalance (Lee \& Hu, 1993b). Medical and psychological research is now providing evidence of the healthfulness of Qi Gong practice (Guadalupe et al., 2017; Hiraoka et al., 1997; Jiang, 1992; Lee \& Hu, 1993a).

Since mind and Qi are intimately related Qi Gong practice can also enhance mental clarity and perception and like other forms of meditation is useful for spiritual pursuits. However, this close relationship with the mind also means that for certain types of Qi Gong, if practiced improperly or by the wrong person, can adversely affect the mind. While Qi Gong practice is understood to be a possible cause of psychosis, the cultural understanding of the psychotic experience itself is related to conceptions of the body and its inherent energy seen in traditional Chinese medicine. Interestingly enough, traditionally, severe mental illness has been identified for at least 1000 years as a possible negative side effect of improper Qi Gong practice ${ }^{1}$.

Lim and Lin (1996) present an example of Qi Gong psychosis in the case a 57-yr-old married ChineseAmerican male Qi Gong practitioner. After practicing Qi gong for three weeks, he began to hear voices commanding him to perform Qi Gong movements in a certain way. The patient was certain that these voices emanated from beings in another dimension. He was diagnosed with schizophreniform disorder and was treated with a neuroleptic drug that improved his symptoms. The authors were not able to conclude whether the abatement of the patient's symptoms was due to the medication or the cessation of Qi Gong practice. In a similar vein, Kuijpers et. al. (2007) describe a case of meditation-induced acute polymorphic psychosis. He concludes that meditation can be a stressor that triggers a brief reactive psychosis. Ng (1999), in a review of Qi gong-induced mental disorders, also concludes that such psychotic episodes are culture-bound but that cultural elements serve as a stressor than can trigger a psychotic break in vulnerable people.

\section{Amafufunyana}

Neihaus (2004) cites two syndromes, amafufunyana (possession by evil spirits) and the related ukuthwasa (coming out or gradually appearing ${ }^{2}$ ), which occur in a number of tribes such as the Xhosa and Zulu, in South Africa, as examples of culture-bound syndromes that are used to explain psychotic or schizophrenic behavior and symptoms.

Amafufunyana is a syndrome where people believe they have been possessed by evil spirits (usually more than one). This possession is brought about by malicious enchantment, where a witch finds ants that have been living in a graveyard, and by association, feeding on dead people. These ants are collected and mixed up into a poisonous idliso or muthi, which is some type of substance that victims ingest or come into contact with, usually through walking over it or having it blown into their face ${ }^{3}$. In

1 For some interesting descriptions of Qi Gong induced psychiatric symptoms see Frantzis (1993). Especially fascinating are the dangers of 'Crane' style vibrating Qi Gong practices. It is interesting to note that many of the techniques for generating power found in traditional Okinawan Karate may be related to this type of Crane Qi Gong practice (Sells, 2000).

${ }^{2}$ Unkuthwasa is in many cases related to the appearance of ancestral spirits related to a specific clan. In this instance the experience of the syndrome can be part of the training and initiation of novice healer (Tropp, 2003).

${ }^{3}$ In fact, the act of blowing into the palm is commonly used to indicate that someone is a witch. 
some cases, even dreaming about ingesting the substance in enough to cause the disorder (Ashforth, 2005).

After the victim has been exposed to the idliso they begin to experience the symptoms of the syndrome. These include hearing voices, often from the stomach and in a different language than one's own, agitation, fatigue, loss of appetite, impulsive anger and aggression, difficulty sleeping, nightmares, and suicidal behavior. The voices can become commanding, threatening, or persecutory, and at times take on the character of someone else, presumably one of the evil spirits possesing the victim. Like some kinds of psychoses, amafufunyana can manifest en mass. One case documented by Edwards (1984) described 400 children who were affected over a two-year period who supposedly suffered from amafufunyana. The children exhibited painful, swollen bellies, ran out of control, rolled their eyes, and lashed out wildly. One teacher reported that if the children's bellies were squeezed, voices claiming to be the possessing spirits could be heard speaking in Zulu. In terms of Western psychology amafufunyana seems very much like a form of psychosis, but also includes elements of somatic, dissociative, and impulse control pathologies (Spanos \& Gottlieb, 1979).

For the Xhosa and Zulu people these syndromes provide an emic account that gives meaning to the disorder in a way that is understood by the person who is suffering (Ensink \& Robertson, 1996). Although sufferers may contextualize the syndrome according to cultural beliefs this does not prevent them necessarily from obtain relief through Western biomedical approaches to treatment (Allen et al., 2004). In addition, the traditional cultural belief system was able to consistently differentiate between psychotic and non-psychotic syndromes (Edwards, 1984). For example, in tribes in the North part of South Africa faith healers make a distinction between madness (bogafi) and amafufunyana. In fact, the treatment of mental illness (which encompasses both bogafi and amafufunyana) is one of the largest specialties practiced by faith healers in the Northern provinces (Peltzer, 1999).

At the turn of the century faith healers (and in some instances the Christian Church) tended to see phenomena like amafufunyana as having supernatural causes while Western psychology and sociology did not. A good example of this was a case of mass amafufunyana at an Anglican school where both the traditional healers and the church placed the blame for the epidemic on possession by evil spirits. However, a Western authority blamed the outbreak on rapid social changes leading to extreme stress and characterized the epidemic as a case of mass hysteria (Parle, 2003). A more recent study found that even with different theoretical orientations, traditional healers and modern psychologists agreed both in diagnosis and treatment modalities given limited options. Patients found both traditional healers and modern psychology about equally as helpful (Carré et al., 2011).

\section{Saora Disorder}

This is a disorder that occurs among young people (teenagers to young adults) of the Saora (sometimes spelled Sora) tribe in the Andhra State along the southeast coast of India. Some Saora people also live in the hill country of Jharkhand and in Maharashtra and Madhya Pradesh. This disorder has a number of features in similar to schizophrenia such as crying and laughing at inappropriate times, loss of memory, and a delusional belief in the presence of supernatural beings who communicate with them. The disorder also has other features such as passing out and the sensation of being bitten by ants in the absence of any insects. The Saora people explain the disorder as being caused by supernatural spirit beings or gods. It is believed that these gods choose young people for a sort of spiritual wedding. This wedding in no way prevents or invalidates romantic relationships and marriage with other human beings, but instead entail the person and god being connected throughout life. If a young person refuses to marry a god, or there is some disagreement among the gods over whom should marry whom, the supernatural beings then cause the symptoms. If the young person marries a god, then the symptoms will cease. It is thought that young people who have gone through the disorder have some ability to be sensitive to the spirit world and are therefore will make good shamans. The local village shaman will take those who come through the disorder as apprentices training them to heal people by intervening with the supernatural forces. Among the Saora becoming a shaman bestows status and respect upon the young person so chosen for this profession (Krippner, 2019).

It should be noted that the Saora have their own gods which may or may not be related to the larger Hindu culture that the Saora exist in. It is thought that the Saora were once a dominant tribe in 
southern India that possessed a complicated culture. However, over the ages they have become diminished compared to their past and consistent mostly of farmers (Elwin, 1955). There has been a push by Hindu nationalists to convert the Saora to Hinduism which has caused considerable conflict. Some Saora have also been converted to Christianity (Vitebsky, 1993, 2017).

It is possible that the young people afflicted with the disorder are experiencing a psychotic break that may be triggered by societal stressors and conditions. The Saora are mainly poor subsistence farmers and young people born into this society have little chance of a life other than what their parents have. This may be worse if the young person is a woman since the Saora tend towards polygamy and are endogamous, marrying within the tribe. A young woman may be married to a man who has multiple wives which could further constrain her position in the family. It may be that the symptoms of Saora disorder may be related to the rather bleak outlook that is the fate of most Saoras in their teens and early 20s. They might want to leave the village, seek out an education, move to a bigger city for employment, and not live their lives as subsistence farmers, but are under intense psychological and social pressure not to do these things. The symptoms of the disorder may serve as sort of a pressure relief valve and a way out of the fate that awaits them. Resolution of the sickness often results in a change of career path, i.e., becoming a Shaman which, we can assume is preferable to subsistence farming. Interestingly, a similar sort of dynamic was found among ultraorthodox Jewish patients who experienced a psychotic break within a month of marriage (Fisch, 1992).

\section{Discussion}

These are just a few examples from around the world and many more could have been included. Disorders like Koro (Ramamourty et al., 2014), Dhat (Udina et al., 2013), Susto (Consoli et al., 2013), Abidjan-Niger Psychosis (Verlingue, 1986), Ataque and Nervios (Lewis-Fernáandez, 1996), Phi Pob (Suwanlert, 1976), etc., have been related to psychosis. Some of these other disorders are clearly variants of psychosis while we can be less sure of others. Given lack of diagnostic precision and uncertainty it becomes easy to attribute many different culturally related syndromes and phenomena to some sort of variation of schizophrenia. An example might be found in Phi Pob, which occurs in Thailand, is a form of sprit possession in which a person is inhabited by a spirit, but the spirit can also possess others nearby. This form of delusion has some similarities to Capgras syndrome where the sufferer believes that people close to them have been taken over by imposters (Berson, 1983).

Conversely, we also see attribution of known forms of psychosis to some sort of cultural uniqueness. An instance of the latter can perhaps be found with Abidjan-Niger Psychosis which occurs among migrant workers in what is now Burkina Faso. This disorder has been described as an acute polymorphic psychotic disorder. It is thought to occur among individuals who have anal compulsive character organization (Verlingue, 1986). While there were some cultural elements to the delusions, which were chiefly persecutory, the disorder presents much like brief reactive psychosis and resolves quickly with medication. Susto, Ataque, and Nervious are likely cultural variants of acute and post traumatic disorders as well as anxiety disorders rather than schizophrenia. Koro and Dhat have more in common with body dysmorphic disorder than with schizophrenia even though they have strong delusional symptomology.

The culture-bound forms of psychosis described here could also be seen as overlapping with other disorders. However, they present a number of etiological factors that seem to cross cultural boundaries. Oedipal distortion in the family can be seen among the Irish, Italian, and Ojibwa versions of psychosis. Clearly early family dynamics play a role in determining the specific symptoms and traits of the psychosis. Italian schizophrenic patients and Wendigo suffers appear to express more hostility. For the Irish and the Saora, religious and cultural restraint in the sufferers appears to play an important role. The Xhosa, Zulu, Ojibwa, and Saora include an element of spirit possession which adds a flavor of dissociation to their forms of psychosis. Qi gong psychosis may have more in common with AbidjanNiger Psychosis where a stressor can trigger a psychotic reaction. 


\section{Conclusion}

Schizophrenia is an intense, and widespread mental illness. It has a complex epidemiology with serious co- morbidities and mortalities. Schizophrenic symptomology and presentation vary across culture and are related to culturally determined family dynamics, religious beliefs, attribution of the origins of the disorder and immigration status. From the above examples of schizophrenia-like culture-bound disorders, it can be seen that it is important for both clinicians and researchers to explore not only the symptomatology of schizophrenia, but also how it manifests in different cultures. These examples argue against a 'one size fits all' approach to understanding and possibly treating psychotic variation around the world. Understanding of religious beliefs, indigenous treatments, local medical and healing practices, as well as culturally determined family structures and external social stressors on specific cultural groups should become part of the training of mental health professionals, who increasingly are treating patients in an ever-shrinking world.

\section{References}

1. Allen, M., Naka, K., \& Ishizu, H. (2004). Attacked by the gods or by mental illness? Hybridizing mental and spiritual health in Okinawa. Mental Health, Religion \& Culture, 7(2), 83-107. https://doi.org/10.1080/ 1367467031000101019

2. American Psychiatric Association. (2000). Diagnostic and Statistical Manual of Mental Disorders, 4th Edition, Text Revision (4th edition). American Psychiatric Association.

3. American Psychiatric Association. (2013). Diagnostic and Statistical Manual of Mental Disorders, 5th Edition: DSM-5 (5 edition). American Psychiatric Publishing.

4. Ashforth, A. (2005). Muthi, Medicine and Witchcraft: Regulating "African Science" in Post-Apartheid South Africa? Social Dynamics, 31(2), 211-242.

5. Berson, R. J. (1983). Capgras' syndrome. The American Journal of Psychiatry, 140(8), 969-978. https://doi.org/10.1176/ajp.140.8.969

6. Bhavsar, V., \& Bhugra, D. (2008). Religious delusions: Finding meanings in psychosis. Psychopathology, 41(3), 165-172. https://doi.org/10.1159/000115954

7. Brekke, J. S., \& Barrio, C. (1997). Cross-Ethnic Symptom Differences in Schizophrenia: The Influence of Culture and Minority Status. Schizophrenia Bulletin, 23(2), 305-316. https://doi.org/10.1093/schbul/23.2.305

8. Carré, J. M., McCormick, C. M., \& Hariri, A. R. (2011). The social neuroendocrinology of human aggression. Psychoneuroendocrinology, 36(7), 935-944. https://doi.org/10.1016/j.psyneuen.2011.02.001

9. Cary, B. (1996). The Wendigo. In Tales from Jackpine Bob (NED-New edition, pp. 111-117). University of Minnesota Press; JSTOR. https://www.jstor.org/stable/10.5749/j.ctttv23v.15

10. Çetingök, M., Chu, C., \& Park, D. (1990). The effect of culture on the sex differences in schizophrenia. International Journal of Social Psychiatry, 36(4), 272-279. https://doi.org/10.1177/002076409003600405

11. Consoli, A. J., Tzaquitzal, M. de los Á. H., \& González, A. (2013). Mayan cosmovision and integrative counseling: A case study from Guatemala. In S. Poyrazli \& C. E. Thompson (Eds.), International case studies in mental health. (2012-13614-008; pp. 141-153). Sage Publications, Inc.

12. Devinsky, O., \& Lai, G. (2008). Spirituality and religion in epilepsy. Epilepsy \& Behavior, 12(4), 636-643. https://doi.org/10.1016/j.yebeh.2007.11.011

13. Dion, G. L., \& Dellario, D. (1988). Symptom subtypes in persons institutionalized with schizophrenia: Comparison of demographics, outcome and functional skills. Rehabilitation Psychology, 33(2), 95-104. https://doi.org/10.1037/h0091684

14. Edwards, F. S. (1984). Amafufunyana spirit possession: A report on some recent developments. Religion in Southern Africa, 5(2), 3-16.

15. Elwin, V. (1955). The religion of an Indian tribe (First Edition edition). Oxford University Press.

16. Ensink, K., \& Robertson, B. (1996). Indigenous categories of distress and dysfunction in South African Xhosa children and adolescents as described by indigenous healers. Transcultural Psychiatric Research Review, 33(2), $137-172$.

17. Fearon, P., Kirkbride, J. B., Morgan, C., Dazzan, P., Morgan, K., Lloyd, T., Hutchinson, G., Tarrant, J., Fung, W. L. A., Holloway, J., Mallett, R., Harrison, G., Leff, J., Jones, P. B., \& Murray, R. M. (2006). Incidence of 
schizophrenia and other psychoses in ethnic minority groups: Results from the MRC AESOP Study. Psychological Medicine, 36(11), 1541-1550. https://doi.org/10.1017/S0033291706008774

18. Fisch, R. Z. (1992). Psychosis precipitated by marriage: A culture-bound syndrome? British Journal of Medical Psychology, 65(4), 385-391. https://doi.org/10.1111/j.2044-8341.1992.tb01719.x

19. Frantzis, B. K. (1993). Opening the Energy Gates of Your Body. North Atlantic Books.

20. Furnham, A., \& Wong, L. (2007). A cross-cultural comparison of British and Chinese beliefs about the causes, behaviour manifestations and treatment of schizophrenia. Psychiatry Research, 151(1), 123-138. https://doi.org/10.1016/j.psychres.2006.03.023

21. Gibson, E. L., Barr, S., \& Jeanes, Y. M. (2013). Habitual fat intake predicts memory function in younger women. Frontiers in Human Neuroscience, 7, 838. https://doi.org/10.3389/fnhum.2013.00838

22. Guadalupe, L. A. O., Miranda, R. T., Soto Prada, K.-J., Borrero, T. C., Cortes Peña, O. F., Scarpati, M. P., \& Ucrós Campo, M. M. (2017). Incidencia de Mindfulness y Qi Gong sobre el Estado de Salud, Bienestar Psicológico, Satisfacción Vital y Estrés Laboral = Incidence of mindfulness and qi gong on the state of health, psychological well-being, life satisfaction and work stress. Revista Colombiana de Psicología, 26(1), 99-113. https://doi.org/10.15446/rcp.v26n1.54371

23. Hagen, C. A., \& Schokking, I. D. (1990). Hysteria and Conversion in the Ojibway Patient: Cross-Cultural Psychiatry for the Family Physician. Canadian Family Physician, 36, 275-279.

24. Hallowell, A. I. (1936). Psychic stresses and culture patterns. American Journal of Psychiatry, 92(6), 1291-1310. https://doi.org/10.1176/ajp.92.6.1291

25. Hiraoka, A., Kobayashi, H., Shimono, F., \& Ohsuga, M. (1997). Effects of Kai-Gou (air-ball handling), a QiGong strategy, on the biofeedback training for enhancement of the electroencephalographic $\alpha$-activity. Japanese Journal of Biofeedback Research, 24, 74-78.

26. Hutchinson, G., Bhugra, D., Mallett, R., Burnett, R., Corridan, B., \& Leff, J. (1999). Fertility and marital rates in first-onset schizophrenia. Social Psychiatry and Psychiatric Epidemiology, 34(12), 617-621. https://doi.org/ $10.1007 / \mathrm{s} 001270050183$

27. Hwang, W.-C. (2007). Qi-gong psychotic reaction in a Chinese American woman. Culture, Medicine and Psychiatry, 31(4), 547-560. https://doi.org/10.1007/s11013-007-9065-Z

28. Jiang, Z. (1992). The effects of Qi Gong training on postworkout anxiety, mood state, and heart rate recovery of high school swimmers. Dissertation Abstracts International, 52(10), 3557.

29. Kastrup, M. C., Báez-Ramos, A., Moodley, R., Lubin, D. B., Akram, S., \& Justin, M. (2008). Case incident 10 : Counseling for transition trauma and health concerns. Case Incidents in Counseling for International Transitions., 151-167.

30. Krippner, S. (2019). Shamanism and dreams. In R. J. Hoss \& R. P. Gongloff (Eds.), Dreams: Understanding biology, psychology, and culture., Vol. 2. (2019-17024-065; pp. 706-710). Greenwood Press/ABC-CLIO.

31. Kuijpers, H. J. H., van der Heijden, F. M. M. A., Tuinier, S., \& Verhoeven, W. M. A. (2007). Meditationinduced psychosis. Psychopathology, 40(6), 461-464. https://doi.org/10.1159/000108125

32. Kurihara, T., Kato, M., Reverger, R., \& Tirta, I. G. R. (2006). Beliefs about causes of schizophrenia among family members: A community-based survey in Bali. Psychiatric Services, 57(12), 1795-1799. https://doi.org/ 10.1176/appi.ps.57.12.1795

33. Landes, R. (1938). The abnormal among the Ojibwa Indians. The Journal of Abnormal and Social Psychology, 33(1), 14-33. https://doi.org/10.1037/h0053504

34. Landy, D. (1985). Pibloktoq (hysteria) and Inuit nutrition: Possible implication of hypervitaminosis A. Social Science \& Medicine (1982), 21(2), 173-185. https://doi.org/10.1016/0277-9536(85)90087-5

35. Leão, T. S., Sundquist, J., Frank, G., Johansson, L.-M., Johansson, S.-E., \& Sundquist, K. (2006). Incidence of schizophrenia or other psychoses in first-and second-generation immigrants: A national cohort study. Journal of Nervous and Mental Disease, 194(1), 27-33. https://doi.org/10.1097/01.nmd.0000195312.81334.81

36. Lee, Y., \& Hu, P.-C. (1993a). The effect of Chinese Qi-gong exercises and therapy on diseases and health. Journal of Indian Psychology, 11(1-2), 9-18.

37. Lee, Y., \& Hu, P.-C. (1993b). The effect of Chinese Qi-gong exercises and therapy on diseases and health. Journal of Indian Psychology, 11(1), 9-18.

38. Lewis-Fernáandez, R. (1996). Cultural formulation of psychiatric diagnosis: Case No 02 Diagnosis and treatment of nervios and ataques in a female Puerto Rican migrant. Culture, Medicine, and Psychiatry: An International Journal of Cross-Cultural Health Research, 20(2), 155-163. https://doi.org/10.1007/BF00115860 
39. Lim, R. F., \& Lin, K.-M. (1996). Cultural formulation of psychiatric diagnosis: Case No. 03: Psychosis following Qi-gong in a Chinese immigrant. Culture, Medicine and Psychiatry, 20(3), 369-378. https://doi.org/10.1007/ BF00113825

40. Lindberg, J. (1974). American Eye: Wendigo: A Fiction, a Fantasy. The North American Review, 259(4), 8-11. JSTOR.

41. Luhrmann, T. M. (2007). Social defeat and the culture of chronicity: Or, why schizophrenia does so well over there and so badly here. Culture, Medicine, and Psychiatry: An International Journal of Cross-Cultural Health Research, 31(2), 135-172. https://doi.org/10.1007/s11013-007-9049-z

42. Mausbach, B. T., Bucardo, J., McKibbin, C. L., Goldman, S. R., Jeste, D. V., Patterson, T. L., Cardenas, V., \& Barrio, C. (2008). Evaluation of a culturally tailored skills intervention for Latinos with persistent psychotic disorders. American Journal of Psychiatric Rehabilitation, 11(1), 61-75. https://doi.org/10.1080/ 15487760701853102

43. McGee, H. F. (1972). Windigo Psychosis. American Anthropologist, 74(1/2), 244-246. JSTOR.

44. Mulder, M. B. (2009). Serial monogamy as polygyny or polyandry? Marriage in the Tanzanian Pimbwe. Human Nature, 20(2), 130-150. https://doi.org/10.1007/s12110-009-9060-x

45. Ng, B. Y. (1999). Qigong-induced mental disorders: A review. The Australian and New Zealand Journal of Psychiatry, 33(2), 197-206. https://doi.org/10.1046/j.1440-1614.1999.00536.x

46. Niehaus, D. J. H., Oosthuizen, P., Lochner, C., Emsley, R. A., Jordaan, E., Mbanga, N. I., Keyter, N., Laurent, C., Deleuze, J.-F., \& Stein, D. J. (2004). A Culture-Bound Syndrome "Amafufunyana" and a Culture-Specific Event "Ukuthwasa": Differentiated by a Family History of Schizophrenia and other Psychiatric Disorders. Psychopathology, 37(2), 59-63. https://doi.org/10.1159/000077579

47. Ødegård, Ø. (1932). Emigration and insanity; a study of mental disease among the norwegian born population of minnesota. Levin \& Munksgaard.

48. Opler, M. K. (1959). Culture and mental health; cross-cultural studies. Macmillan.

49. Parle, J. (2003). Witchcraft or Madness? The Amandiki of Zululand, 1894-1914. Journal of Southern African Studies, 29(1), 105-132.

50. Peltzer, K. (1999). Faith Healing for Mental and Social Disorders in the Northern Province (South Africa). Journal of Religion in Africa, 29(3), 387-402.

51. Ptak, S. E., \& Lachmann, M. (2003). On the evolution of polygyny: A theoretical examination of the polygyny threshold model. Behavioral Ecology, 14(2), 201-211. https://doi.org/10.1093/beheco/14.2.201

52. Ramamourty, P., Menon, V., \& Aparna, M. (2014). Koro presenting as acute and transient psychosis: Implications for classification. Asian Journal of Psychiatry, 10, 116-117. https://doi.org/10.1016/ j.ajp.2014.03.008

53. Rohrl, V. J. (1970). A Nutritional Factor in Windigo Psychosis. American Anthropologist, 72(1), 97-101. JSTOR.

54. Rossello, J.-J., Gaillard, G., \& Neuilly, M.-T. (2013). Une institution en quête de limites. Le mythe de Tom Sawyer: Un objet transitionnel collectif. = An institution seeking limits. The myth of Tom Sawyer: A collective transitional object. Revue de Psychothérapie Psychanalytique de Groupe, 60, 141-152. https://doi.org/10.3917/ rppg.060.0141

55. Sanderson, I. T. (1963). Some preliminary notes on traditions of submen in arctic and subarctic North America. Genus, 19(1/4), 145-162. JSTOR.

56. Saravanan, B., Jacob, K. S., Johnson, S., Prince, M., Bhugra, D., \& David, A. S. (2007a). Assessing insight in schizophrenia: East meets West. British Journal of Psychiatry, 190(3), 243-247. https://doi.org/10.1192/ bjp.bp.106.029363

57. Saravanan, B., Jacob, K. S., Johnson, S., Prince, M., Bhugra, D., \& David, A. S. (2007b). Belief models in first episode schizophrenia in South India. Social Psychiatry and Psychiatric Epidemiology: The International Journal for Research in Social and Genetic Epidemiology and Mental Health Services, 42(6), 446-451. https://doi.org/10.1007/s00127-007-0186-z

58. Sells, J. (2000). Unante (2nd edition). W.M. Hawley.

59. Simpson, M. A. (1995). Gullible's travels, or the importance of being multiple. Dissociative Identity Disorder: Theoretical and Treatment Controversies., 87-134.

60. Spanos, N. P., \& Gottlieb, J. (1979). Demonic Possession, Mesmerism, and Hysteria: A Social Psychological Perspective on Their Historical Interrelations. Journal of Abnormal Psychology, 88(5), 527-546.

61. Suwanlert, S. (1976). Neurotic and psychotic states attributed to Thai "phii pob" spirit possession. Australian and New Zealand Journal of Psychiatry, 10(1-A), 119-123. 
62. Tropp, J. (2003). The Python and the Crying Tree: Interpreting Tales of Environmental and Colonial Power in the Transkei. The International Journal of African Historical Studies, 36(3), 511-532.

63. Udina, M., Foulon, H., Valdés, M., Bhattacharyya, S., \& Martín-Santos, R. (2013). Dhat syndrome: A systematic review. Psychosomatics: Journal of Consultation and Liaison Psychiatry, 54(3), 212-218. https://doi.org/10.1016/j.psym.2012.09.003

64. Verlingue, M. (1986). Haute-Volta et "Psychose Abidjan-Niger" = Upper-Volta and "Abidjan-Niger" psychosis. Psychologie Medicale, 18(1), 93-96.

65. Vitebsky, P. (1993). Dialogues with the Dead: The Discussion of Mortality among the Sora of Eastern India. Cambridge University Press.

66. Vitebsky, P. (2017). Living without the Dead: Loss and Redemption in a Jungle Cosmos (1 edition). University of Chicago Press.

67. Volavka, J., Laska, E., Baker, S., Meisner, M., Czobor, P., \& Krivelevich, I. (1997). History of violent behaviour and schizophrenia in different cultures: Analyses based on the WHO study on Determinants of Outcome of Severe Mental Disorders. British Journal of Psychiatry, 171(1), 9-14. https://doi.org/10.1192/bjp.171.1.9

68. Volkan, K. (2020). Schizophrenia: Epidemiology, Causes, Neurobiology, Pathophysiology, and Treatment. Journal of Health and Medical Sciences, 3(4), 487-521. https://doi.org/10.31014/aior.1994.03.04.143

69. Weisman, A. G., \& López, S. R. (1997). An attributional analysis of emotional reactions to schizophrenia in Mexican and Anglo American cultures. Journal of Applied Social Psychology, 27(3), 223-244. https://doi.org/ 10.1111/j.1559-1816.1997.tb00630.x

70. White, T., Cullen, K., Rohrer, L. M., Karatekin, C., Luciana, M., Schmidt, M., Hongwanishkul, D., Kumra, S., Schulz, S. C., \& Lim, K. O. (2008). Limbic structures and networks in children and adolescents with schizophrenia. Schizophrenia Bulletin, 34(1), 18-29. https://doi.org/10.1093/schbul/sbm110 